\title{
A CONTRIBUTION TO THE KNOWLEDGE OF THE EXCRETION OF ORGANIC PHOSPHORUS IN THE URINE IN CERTAIN PATHOLOGICAL CON- DITIONS.
}

\author{
By Douglas Symarks.
}

From the Strecker Memorial Laboratory of the New York City (Charity) Hospital.

UxTIL very recent years it was thought that the excretion in the urine of phosphorus, in organic combination, is so insignificant in quantity as to be negligible both in health and in disease. Recent investigations, however, have revealed organic compounds of phosphorus in considerable quantities in the urine. This fact, taken in connection with the contradictory statements concerning nuclein metabolism as a whole, more especially in diseased conditions, is deemed sufficient to render a more careful and definite study of the subject desirable.

Some of the older observations were based mainly upon the assumption that the total phosphorus output in the urine was practically equivalent to the output of the inorganic salts, and that the occurrence of organic compounds could be ignored without detracting in any degree from the value of the final determination. On the other hand, there have been occasional attempts to define the real significance of organic phosphorus. For example ( $\left.{ }^{1}\right)$, Lépine, Eymonnet, and Aubert, in a number of single observations, found that in certain lesions the amount of organic phosphorus in relation to nitrogen and the inorganic phosphates was increased, e.g., in hysteria, hystero-epilepsy, apoplexy, and delirium tremens. In a number of other lesions, e.g. meningitis, they found a diminution of organic phosphorus to nitrogen, with or without relative increase in the phosphoric acid. Similar observations have been made by Zuilzer $\left({ }^{2}\right)$. But such facts are too few, too isolated and indefinite, and have attracted but little attention, probably because, until recent years, so very little was known of the normal output of organic phosphorus in the urine.

Lately, however, Horst Oertel $\left(^{3}\right)$ has shown that a normal individual, living on an ordinary mixed diet, excretes in the urine in twenty-four hours about 2 grms. of total phosphorus, expressed in terms of $\mathrm{P}_{2} \mathrm{O}_{5}$, and that, of this quantity, about $0.05 \mathrm{grm}$. exists in organic

11-JL. of Path.-VoL. $x$. 
combination, probably largely as glycero-phosphoric acid $\left(^{4}\right)$, and also, perhaps, in the form of the more highly phosphorised substances, such as the lecithins. While this amount of organic phosphorus may be taken as the average output, considerable variations may occur; the largest output under normal conditions having been found not to exceed $0.12 \mathrm{grm}$. in twenty-four hours. Under normal conditions, then, the organic phosphorus represents from $2 \cdot \overline{\mathrm{s}}$ per cent. to about 4 per cent of the total quantity of phosphorus excreted in the urine. The fact has also been established that the relation of the total nitrogen excretion to that of organic phosphorus varies between 0.1 per cent. and 0.5 per cent. As a rule, individuals with higher nitrogen figures show larger figures for organic phosphorus, but an absolute parallelism does not occur.

In considering the source of organic phosphorus, several possibilities have to be considered. It may be that it is derived from food, or that it is a product of metabolism, or that both factors are concerned in its production, as is exemplified in the formation of uric acid and of the xanthin bases, which are both endogenous and exogenous in origin. Important work bearing directly on this question has been done by Keller $\left({ }^{5}\right)$, who studied the question of the excretion of phosphorus in the urine of infants. Keller found the absolute figures proportionately smaller in infants than in adults, but relatively larger in proportion to weight and nitrogen excretion. There was the same lack of absolute parallelism between nitrogen and organic phosphorus.

Formerly the output of organic phosphorus in the urine was thought to depend directly upon the disintegration of nervous structures. But in the light of the observations by Oertel, and by Keller, this must be regarded as fallacious, mainly because of the variations that have been found to exist even under normal conditions. Still further confirmation arises from the variations that have been found in certain pathological conditions, as outlined below.

The investigation of the influence of food on the excretion of organic phosphorus made by Keller revealed the fact that the quantity of phosphorised organic compounds in the food has practically no relation to their excretion in the urine. Loewy has shown that, while nucleins are absorbed with their phosphorus in organic combination, no influence is exerted on the excretion of organic phosphorus in the urine. Confirmatory evidence is offered by Gumlich $\left({ }^{6}\right)$, and by Mandel and Oertel $\left({ }^{7}\right)$. The two last observers have demonstrated that a diet absolutely phosphorus free, such as rice, and one rich in organic phosphorised compounds, such as calf's brain, shad roe and meat, while exerting a decided influence on the excretion of nitrogen, leave the excretion of organic phosphorus untouched. This is strikingly shown in their tables, of which an example is given on the opposite page (Table I.).

It may, then, be regarded as certain that the exogenous factor is 
entirely foreign to the question of the excretion of organic phosphorus in the urine. Finally, it has been shown that active muscular exercise is also without effect.

TABle I.

\begin{tabular}{|c|c|c|c|c|c|c|c|c|c|}
\hline Diet. & & Day. & Quantity. & $\begin{array}{l}\text { Total } \\
\text { N. }\end{array}$ & $\begin{array}{l}\text { Total } \\
\mathrm{P}_{2} \mathrm{O}_{5}\end{array}$ & $\underset{\mathrm{P}_{2} \mathrm{O}_{3}}{\text { Organic }}$ & $\begin{array}{c}\mathbf{x} \\
\text { Total } \\
P_{: 2} O_{0 .}\end{array}$ & $\begin{array}{c}\mathrm{N}: \\
\quad \text { Organic } \\
\mathbf{P}_{2} \mathrm{O}_{b} .\end{array}$ & $\begin{array}{l}\text { Percentage. } \\
\text { Total P O } \\
\text { as Organic. }\end{array}$ \\
\hline \multirow{4}{*}{ Rice. } & & 1 & 1360 c.c. & $7 \cdot 97$ & 1.59 & 0.015 & $100: 20$ & $100: 0 \cdot 185$ & $0 \cdot 9$ \\
\hline & & 2 & 1680 & $7 \cdot 94$ & 1.07 & 0.016 & $100: 13 \cdot 5$ & $100: 0.203$ & $1 \cdot 50$ \\
\hline & & 3 & 1820, & $7 \cdot 79$ & 0.94 & 0.016 & $100: 12 \cdot 1$ & $100: 0.209$ & $1 \cdot 70$ \\
\hline & 11 & 4 & 1060 & $5 \cdot 90$ & 0.60 & 0.011 & $100: 10 \cdot 2$ & $100: 0.183$ & $1 \cdot 80$ \\
\hline \multirow{4}{*}{ Shad roe } & & 5 & 960, & $13 \cdot 84$ & $1 \cdot 32$ & 0.019 & $100: 9 \cdot 5$ & $100: 0 \cdot 138$ & $1 \cdot 43$ \\
\hline & 1 & 6 & 830, & $16 \cdot 66$ & $1 \cdot 26$ & 0.016 & $100: 7 \cdot 5$ & $100: 0.0987$ & $1 \cdot 30$ \\
\hline & & 7 & 970, & $18 \cdot 65$ & $1 \cdot 18$ & 0.010 & $100: 63$ & $100: 0.0560$ & 0.87 \\
\hline & 1 & 8 & 850, & $18 \cdot 11$ & $1 \cdot 06$ & 0.014 & $100: 5 \cdot 8$ & $100: 0.0779$ & $I \cdot 33$ \\
\hline
\end{tabular}

Pursuing still further the study of the source of organic phosphorus one must consider, first, its existence in the urine in pathological conditions; and, second, experimental evidence. As far as either is concerned, there is practically nothing in the literature, with the exception of one experiment by Keller, who, having starved himself for four days, found that the excretion of organic phosphorus showed, at first, no departure from the normal; it was then followed by a rather sudden rise from $0.01 \mathrm{grm}$. to $0.05 \mathrm{grm}$. This, of course, suggested that an increased excretion of organic phosphorus may originate in tissue disintegration depending upon starvation, a fortiori, since it is known that in starvation the lymphoid elements are the first to suffer. Further than this, nothing is really known of the source of this substance.

The observations that follow represent the results obtained from a number of analyses of pathological urines, and were made with the purpose of determining, as far as possible-(1) the influence on the excretion of organic phosphorus of diseases in which the lymphatic system is extensively concerned, inasmuch as it is known that this system is rich in nuclein; (2) the influence of nervous diseases; (3) the influence of increased tissue destruction; (4) the influence of conditions attended at once by lessened oxidation and by increased decomposition.

This paper does not attempt to treat the subject exhaustively, but because of the importance of the subject, and in order to obtain the co-operation of others working along similar lines, it seems advisable to put the present observations on record. The results of experi- 
mental work and of further pathological investigation, tending to elucidate the question of the source of organic phosphorus, will be announced at a later date.

In making the various determinations the following methods were employed :-

The total nitrogen by the Kjeldahl method. ${ }^{1}$ The inorganic phosphates by titration with !ranium nitrate, and the total phosphates by titration with the same substance after fusing with sodium hydrate and potassium nitrate, the difference representing the amount of phosphorus in the organic state. Uric acid by the Hopkins-Folin method.

1. In studying the influences of diseases in which the lymphatic system is involved, advantage was taken of a typical case of lymphatic leukæmia occurring in the service of Drs. N. B. Potter and T. C. Janeway at the New York City Hospital.

The patient was a longshoreman, æt. 59 , and single. He was admitted with a temperature of $103^{\circ} \mathrm{F}$., which lasted, however, a few hours only. Physical examination revealed, among other things, great enlargement of the cervical, supra- and infra-clavicular, axillary and inguinal lymphatic glands, and presumptive evidence of involvement of the intrathoracic glands. The visible mucous membranes were blanched, and the skin of the entire body was dusky green or greenish yellow in colour. The spleen was palpable almost as low as the level of the umbilicus. The liver was likewise greatly enlarged, and its left lobe could be differentiated from the spleen only with difficulty. The feet and ankles were odematous, and evidence of the existence of fluid in the abdomen was easily discoverable. An examination of the blood at the time of admission revealed 72,500 leucocytes, a differential count of which exhibited a preponderance of lymphocytes, especially of the large varicty. The red cells numbered $1,536,000$. Poikilocytosis was apparent, but no nucleated red cells were detectel in the course of numerous examinations, until after the lapse of several days. After ten days in the hospital, during which period the patient's temperature was normal, except as noted upon admission, there occurred scidenly and without definable reason a chill lasting half an hour, followed by elevation of temperature to $105^{\circ} \mathrm{F}$. After this the white cells were found to number 568,000 , and the stained specimen contained numbers of nucleated red cells. Except for such periods as the one just described, the patient felt quite well, although slightly weak. There were no digestive disturbances, so that absorption was probably good.

The table of results (Table II.) bearing upon the examination of the urine from this patient, while it largely explains itself, contains a number of points that merit emphasis. It will be observed that the daily output of total phosphates exhibits considerable variations in the absolute figures, ranging from 0.77 grm. to 3.56 grms., as contrasted with the normal output of 2 grms. The percentage of organic phos-

\footnotetext{
1 In the beginning of this study it was not possible to make the total nitrogen determination by the Kjeldahl method, but in order to obtain some information concerning the nitrogen metabolism, urea was determined by the sodium hypobromite method. Becanse of the comparative uncertainty of this method, however, the figures so obtained were not used to establish ratios, but remain merely as absolute values. Later, when it becane practicalie to employ the Kjelduhl apparatus, the total nitrogen excretion was determined in erery instance, and the urea determinations were continued in a few cases for a short time as a neans of comparison.
} 
phorus in the total excretion is seen to be almost always high, varying from 2 per cent. to 89 per cent. This would seem to indicate periods of phosphorus retention followed by an exaggerated output, the whole pursuing a somewhat rhythmical course. In the light of observation that, under normal conditions, a small part of the total phosphorus output exists in organic combination, and because of the discovery in the patient whose case is now under consideration and in other pathological conditions, of both a relative and absolute increase in the excretion of organic phosphorus, often reaching limits heretofore unsuspected, it is difficult to reconcile with the results of this investigation one of the statements occurring in the report of a study of nuclein metabolism in lymphatic leukremia recently made by Henderson and Edwards $\left(^{8}\right)$. These workers state, rather indefinitely, that " in order to discover whether there might not be an elimination of phosphorus in organic combination, a number of determinations were made of the total amount after evaporation of a sample of urine and ignition with sodium hydroxide and potassium nitrate. The results, however, agreed entirely with those obtained by the titration method ": The figures representing the excretion of inorganic phosphates, in the cases now under consideration, taken alone, would hardly indicate the true index of phosphorus metabolism, since, in many instances, they do not represent any decided variation from the normal, but in reality the total output is seen to be much greater when the inorganic and organic compounds are considered together. Lack of consideration of this very point has, I believe, contributed in great measure to the confusion that now obtains concerning nuclein metabolism, for the output of total phosphates and of inorganic phosphates has been regarded as practically identical, so that, as already stated, the determination of the latter has been regarded as equivalent to the determination of the former. From this it appears that no phosphorus determination is in any degree accurate which fails to define both the inorganic and organic compounds excreted. The latter point is illustrated in almost every deternination contained in the following tables, where the percentage of organic phosphorus in the total output is almost always far above the normal.

Returning to the consideration of the table, it is worthy of note that the ratio between the total excretion of nitrogen and the total output of phosphorus is sometimes high and at other times within normal limits. On the other hand, the ratio between the total nitrogen excretion and the output of organic phosphorus is practically always very high, the normal ratio varying between 100:0.0560 and $100: 0.479$, as contrasted with the variations set forth in Tiable II.

2. In nervous lesions of the degenerative type a number of determinations have been made, and the results incorporated in Table III. It is seen that the excretion of organic phosphorus in 


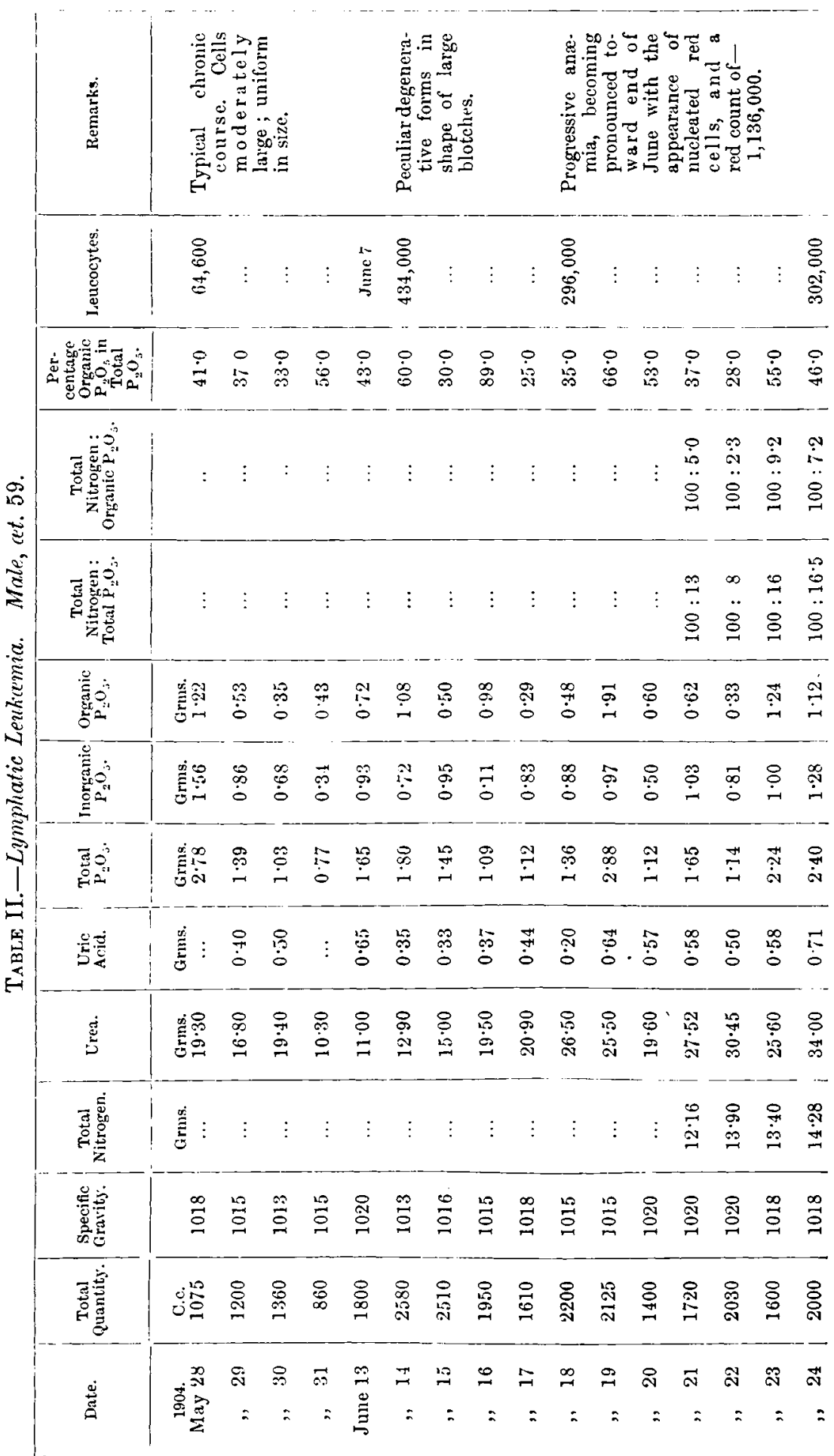




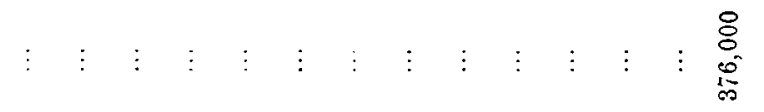

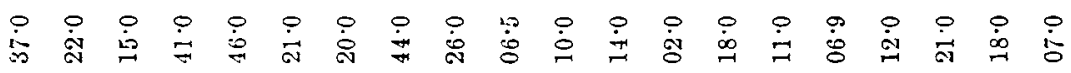

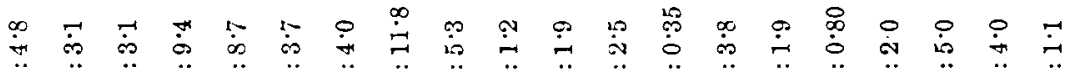

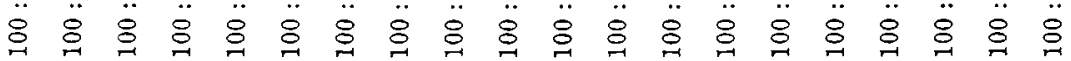

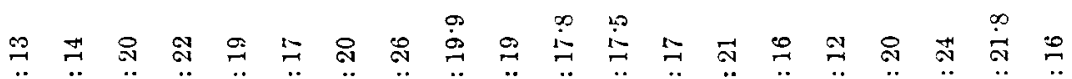

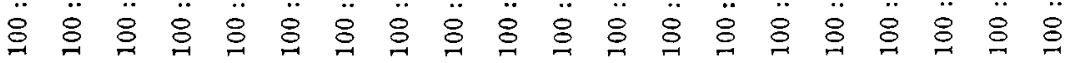

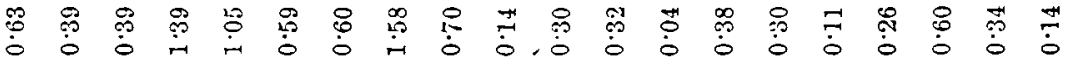

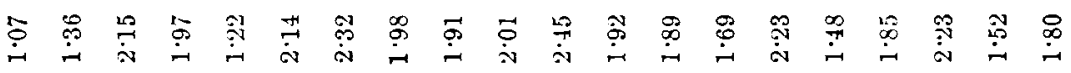

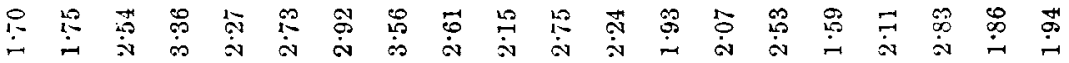

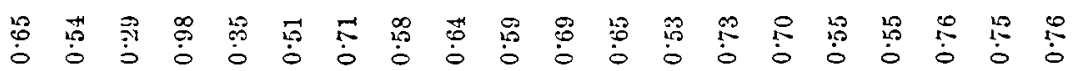
웅 유융 웅 舫

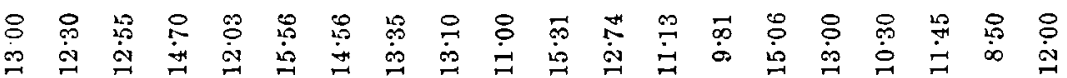

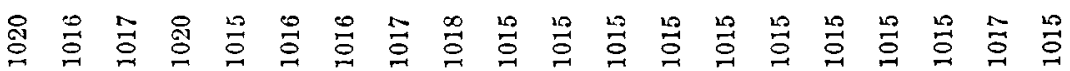

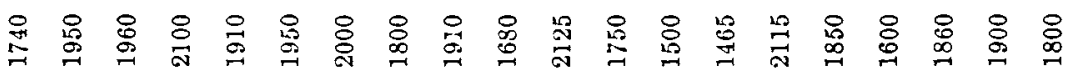

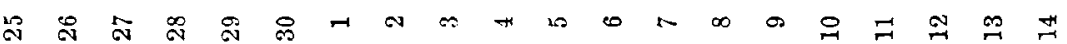

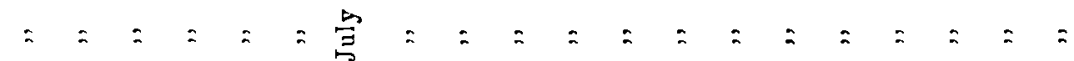




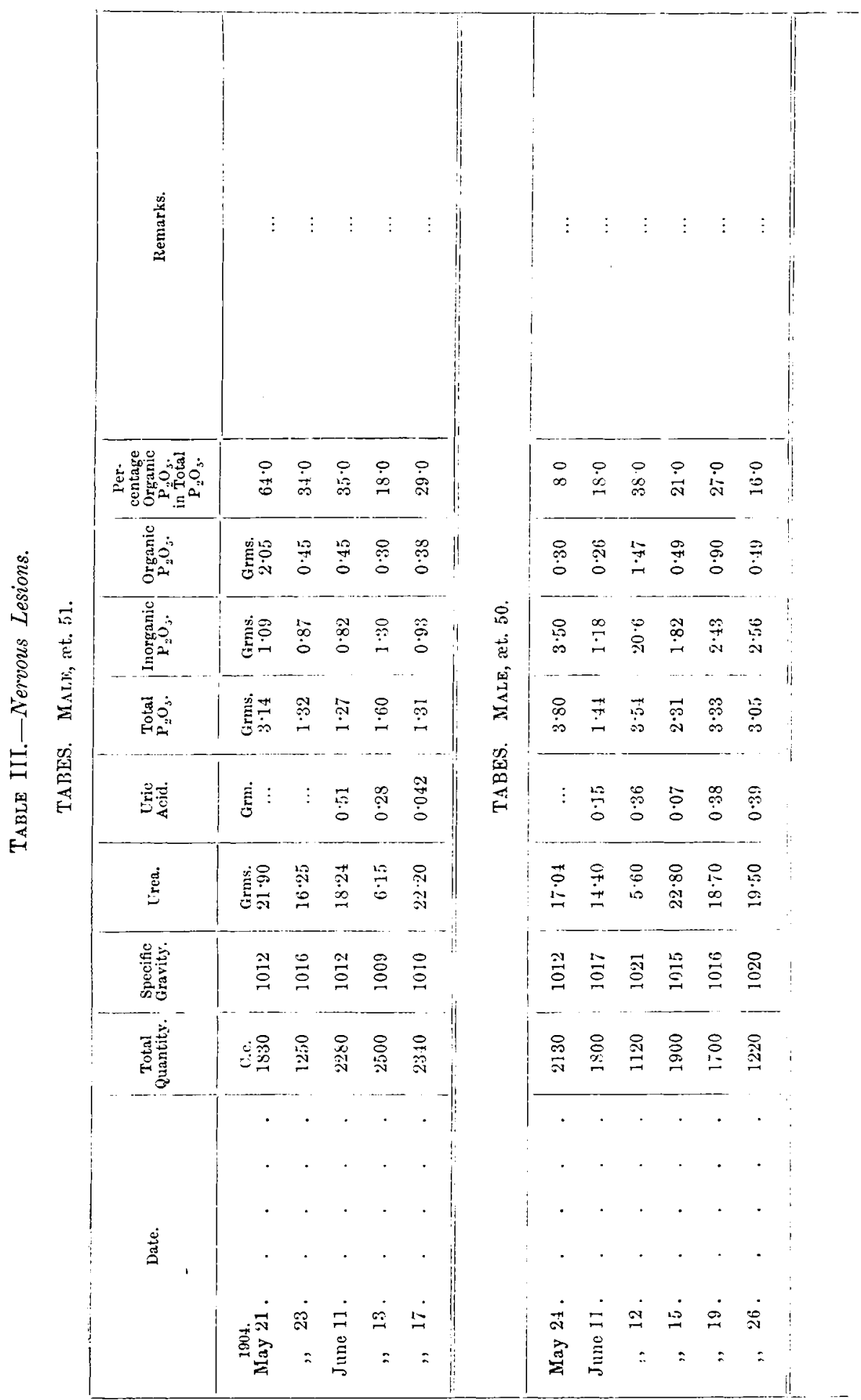




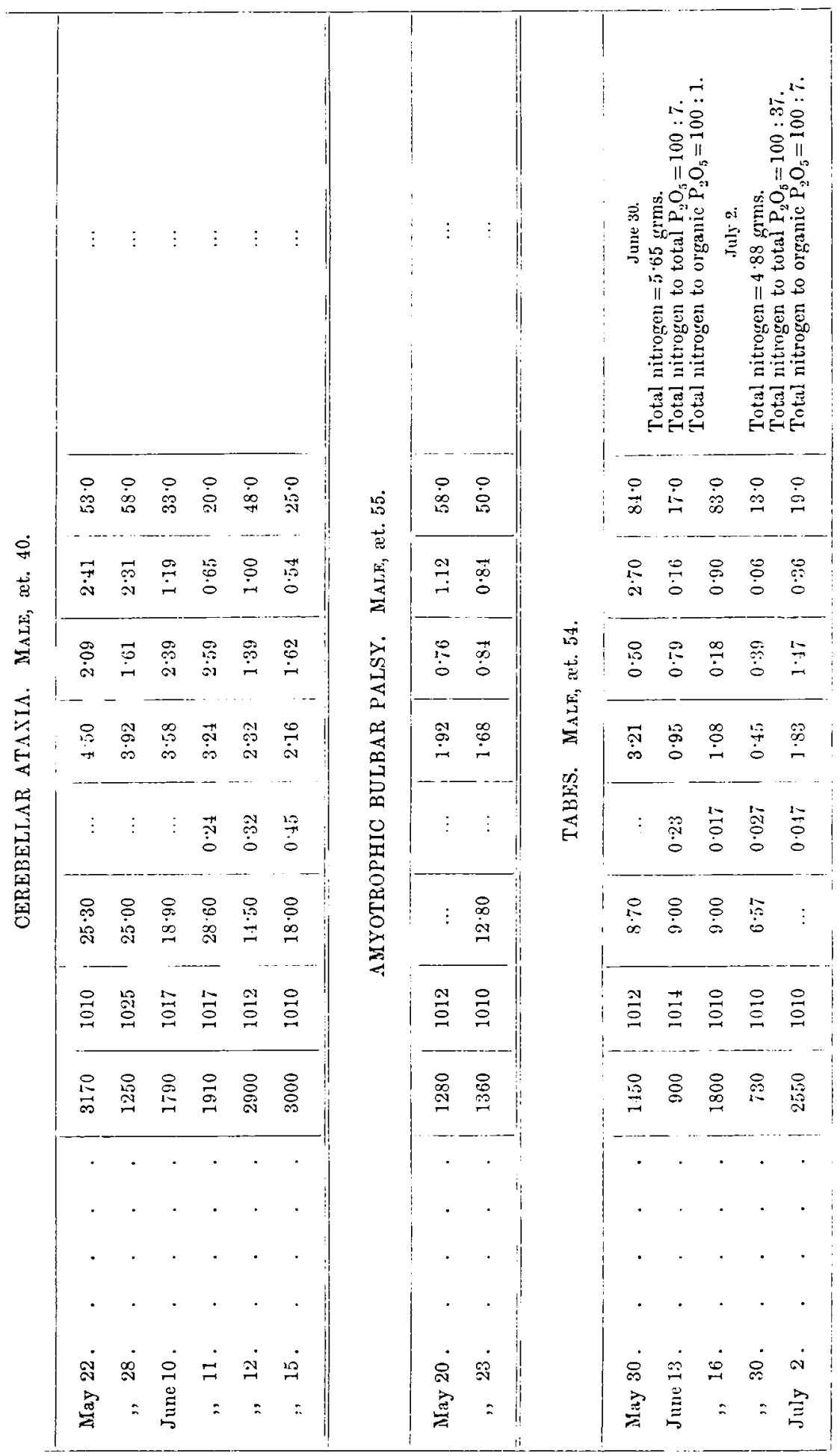




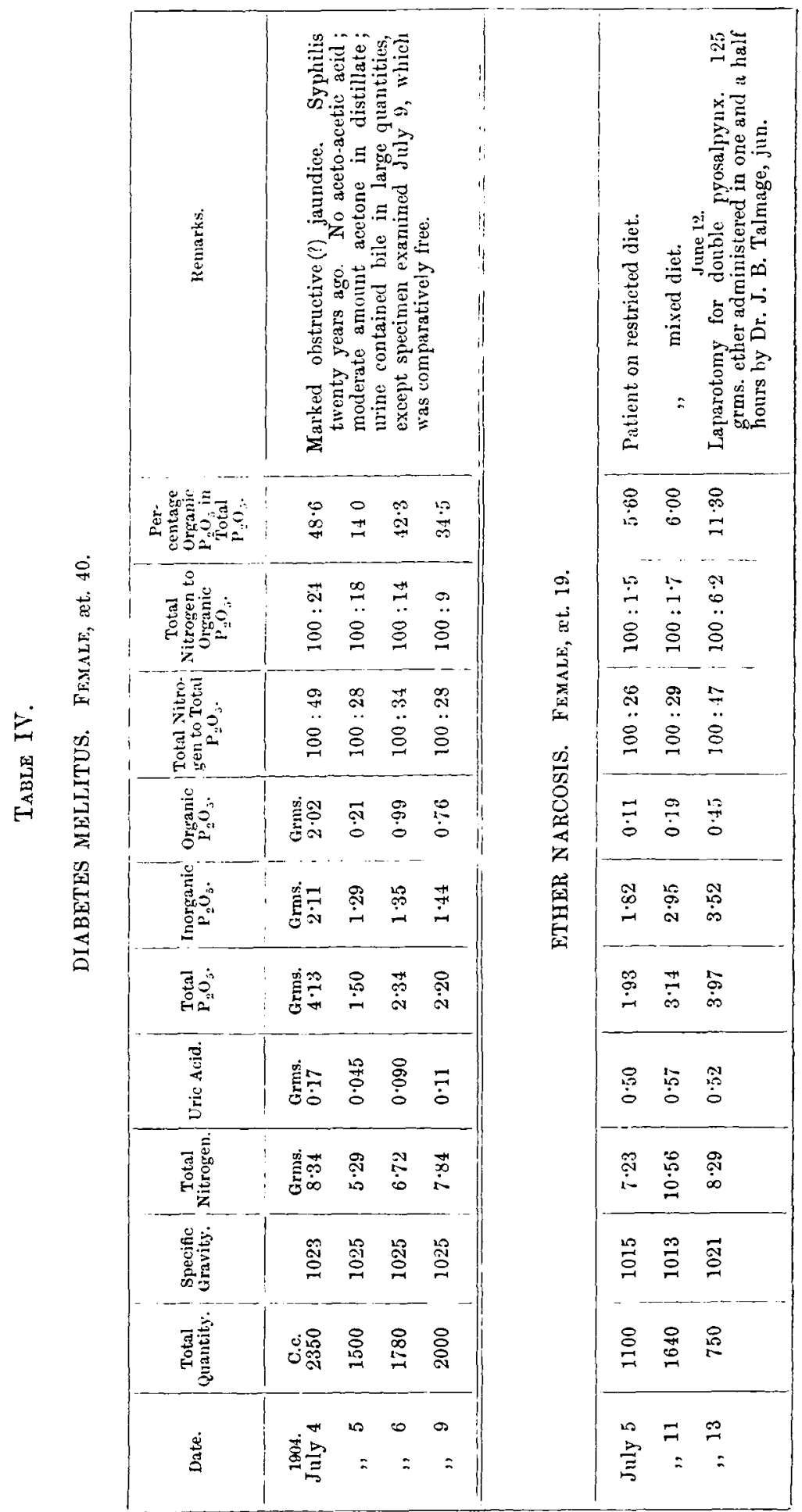




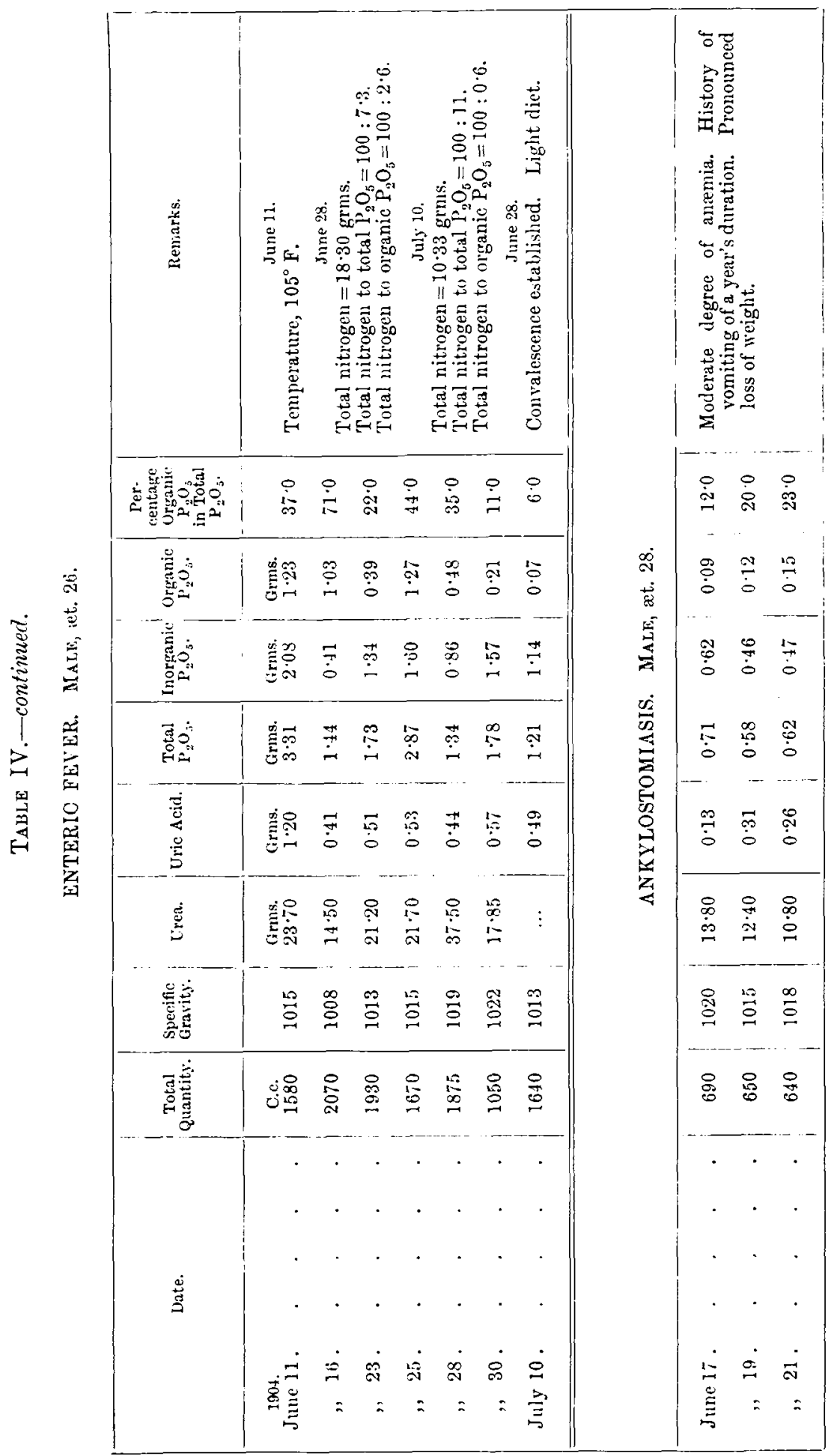




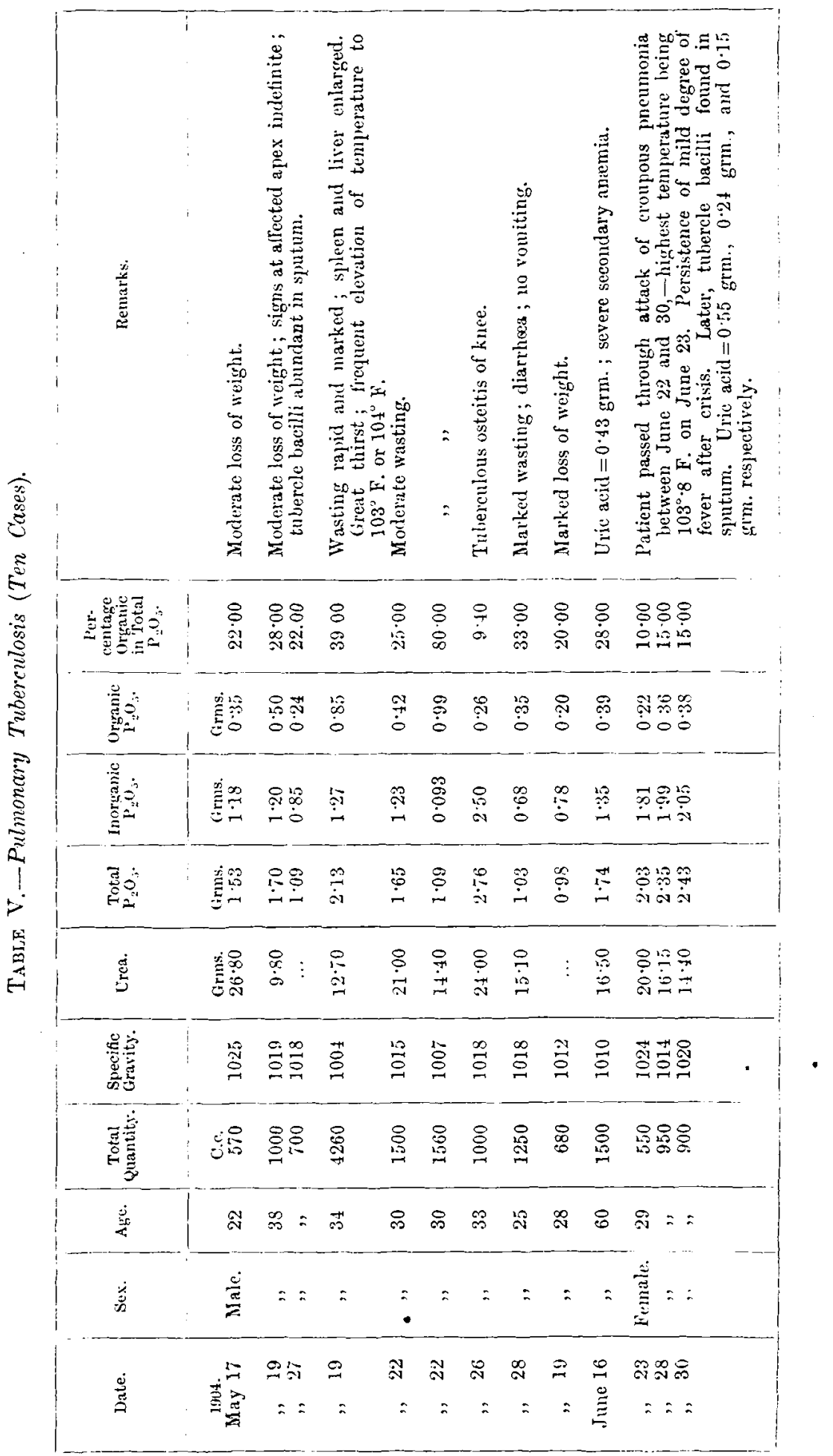


this class of patients is subject to the same wide variation as in the case of the patient with lymphatic leukæmia, the percentage of organic phosphorus in the total output ranging from the extreme normal (?) limit of 8 per cent. in one case to 84 per cent. in another. While no case has been followed from day to day for any length of time, the records already obtained show that there are periods during which such patients conform to the same rhythm of apparent retention and exaggerated excretion. The patient represented in the table as cerebellar ataxia is remarkable in that, on one occasion, he excreted in twenty-four hours 3170 c.c. of urine, containing 2.41 grms. of phosphorus in organic combination, followed a few days later by 1250 c.c. of urine containing $2 \cdot 31$ grms.

3. and 4. In pulmonary tuberculosis (Table V.) and in conditions attended by lessened oxidation and increased decomposition, as in diabetes mellitus (Table IV.), ether narcosis, etc., a few observations have been made, but they cannot be regarded as sufficiently extensive to warrant definite deductions or detailed comment, and, for this reason, are incorporated with the results obtained in several miscellaneous cases, likewise deemed insufficiently investigated.

\section{Conclusions.}

1. That an appreciable and important amount of $\mathrm{P}_{2} \mathrm{O}_{5}$ in organic combination is excreted in the urine in various pathological conditions, so that frequently 25 or 50 per cent., and, in occasional instances, almost all the $\mathrm{P}_{2} \mathrm{O}_{5}$ appears in the organic state. Therefore, the determination of the inorganic $\mathrm{P}_{2} \mathrm{O}_{5}$ cannot be regarded as a true index of phosphorus metabolism.

2. That the excretion of organic $P_{2} \mathrm{O}_{5}$ is to an extent rhythmical, periods of excessive excretion alternating with what may be either retention or diminished production, so that in cases in which an average output is to be established, frequent determinations must be made.

3. That the excretion of organic $\mathrm{P}_{2} \mathrm{O}_{5}$ is pronounced in lymphatic leukimia, where there is a marked change in ratios of nitrogen to organic $\mathrm{P}_{2} \mathrm{O}_{5}$ as well as an absolute increase in the percentage of organic $\mathrm{P}_{2} \mathrm{O}_{5}$ in the total $\mathrm{P}_{2} \mathrm{O}_{5}$, while the ratio of nitroyen to total $\mathrm{P}_{2} \mathrm{O}_{5}$ and to the inorganic $\mathrm{P}_{2} \mathrm{O}_{5}$ shous little if any departure from the normal.

4. In nervous diseases of the degenerative type the absolute amounts of organic $\mathrm{P}_{2} \mathrm{O}_{5}$, as well as their percentage in the total $\mathrm{P}_{2} \mathrm{O}_{5}$, are increased, sometimes to an enormous extent. It seems impossible that such amounts could be derived directly from the destruction of nervous tissues. In this connection the question of trophic influence assumes importance.

5. It seems unlikely that the increased excretion of $\mathrm{P}_{2} \mathrm{O}_{5}$ could be deriverl, as has been suggested, from bone. We have confirmation 
of this statement in the fact that in diseases in which bony structures are directly and extensively involved, e.g. osteomalacia, the output of $\mathrm{P}_{2} \mathrm{O}_{5}$ has not been found increased. The foregoing observations, however, do lend weight to the assumption that the increased phosphorus output depends upon general metabolic causes, probably in the waste of organic phosphorised endogenous compounds. The abnormal increase of the organic $\mathrm{P}_{2} \mathrm{O}_{5}$, as shown especially in the ratio and percentage of organic $\mathrm{P}_{2} \mathrm{O}_{5}$ in the total $\mathrm{P}_{2} \mathrm{O}_{5}$, may be explained in two ways-either it is an increase in the production of phosphorised endogenous metabolic compounds, or an expression of lessened oxidation, with the inorganic phosphates as the end product.

In closing $I$ wish to express my appreciation of the courtesies extended to me by Drs. N. B. Potter, Theodore C. Janeway, and C. N. B. Camac, of the Staff of Visiting Physicians to the New York City Hospital, and to thank those of my colleagues on the Staff of Resident Physicians in this hospital who have given me aid and co-operation, particularly Drs. W. C. Chapin, Robert Ferguson, and A. H. Garvin. To the latter I am especially indebted for clinical data.

Most deeply, however, am I indebted to Dr. Horst Oertel, Director of the Strecker Memorial Laboratory, at whose suggestion this study was undertaken, and under whose direction it has been carried on.

\section{REFERENCES.}

1. Lepine, Emonnet, and Compt. rend. Acad d. sc., Paris, 1884, tome Aubert. xcviii. p. 238.

2. ZüLZZR . . . . . . . "Untersuchungen ueber d. Semiologie des Harns," 1884.

3. Horst Oertel . . . . Ztsclir. f. physiol. Chem., Strassburg, 1898, Bd. xxvi. S. 123.

4. Sotnitschewsk I . . . . Ibid., 1880, Bd. iv. S. 214.

5. Kelter. . . . . . . Ibid., 1900, Bd. xxix. S. 146.

6. GuMlich . . . . . . Ibid., 1894, Bd. xviii. S. 508.

7. Mandel and Oertel . . N.Y. Univ. Bull. Med. Sc., 1901, vol. i. No. iv. p. 165.

8. Henderson and Edwards. Am. Journ. Physiol., Boston, 1903, vol. ix. p. 417. 